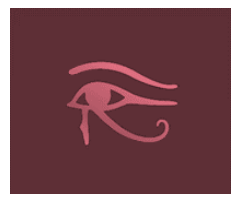

\title{
A EDUCAÇÃO ENCLAUSURADA: REFLEXÕES SOBRE AUTONOMIA RELATIVA E OS MECANISMOS DE RESISTÊNCIA À DOMINAÇÃO NA ESCOLA DO CÁRCERE
}

\author{
Arlindo da Silva Lourenço \\ arlindolourenco@uol.com.br \\ Laboratório de Estudos sobre o Preconceito da USP (LaEP-USP)
}

RESUMO: Este artigo revisita um problema de pesquisa investigado por ocasião da pesquisa de Mestrado levada a efeito entre os anos de 2003 e 2005 acerca das possibilidades de autonomia e os mecanismos de resistência encontrados, principalmente, nos prisioneiros que frequentavam a escola do cárcere. O referencial metodológico partiu de análises etnográficas que incluíram observações de campo em oito penitenciárias em São Paulo que ofereciam a política de EJA, além de entrevistas semiestruturadas com os atores educacionais. Os estudiosos clássicos da prisão, como Foucault e Goffman, bem como da escola, como Barroso, Apple e Nóvoa, orientaram aqueles estudos. As conclusões indicaram, conforme as análises eram realizadas e os resultados surgiam, o quanto a escola no cárcere oferecia, mais que um ambiente "neutro" em relação aos demais locais de circulação de pessoas reclusas, uma arena profícua onde as relações de poder e dominação podem e devem ser debatidas, confrontadas e, quiçá, sublevadas.

PALAVRAS-CHAVE: educação de jovens e adultos presos; autonomia escolar; relações de poder.

\section{ENCLOSED EDUCATION: REFLECTIONS ABOUT AUTONOMY AND RESISTANCE MECHANISMS TO THE DOMINATION IN PRISON SCHOOL}

ABSTRACT: This article reviewed a research problem investigated during the Master's research carried out between 2003 and 2005 about the possibilities of autonomy and the mechanisms of resistance found, mainly, in those prisoners who attended classes at the enclosed school. The methodological framework came from ethnographical analyses which included field observations in eight prisons in São Paulo offering YAE (Youth and Adults Education), a schooling policy program and semi structured interviews with educational actors. The classical scholars of the prison, as Foucault and Goffman, and from school, as Barroso, Apple and Nóvoa, guided those studies. As the analyses were carried out and the results appeared it could be observed how much is offered by the enclosed school, more than a "neutral" environment compared to other places where there is movement of prisoners, a prolific arena where power and domination relations can and shall be debated, faced and, maybe, incited to change.

KEYWORDS: education for youth and adults prisoners; school autonomy; power relations. 
Este artigo, reproduzido com alterações a partir de um capítulo da dissertação de mestrado defendida na Pontifícia Universidade Católica de São Paulo (LOURENÇO, 2005), pretende retomar e atualizar uma discussão sobre a questão da autonomia relativa das escolas nas prisões levando-se em conta certos dispositivos de resistência ao poder institucional por parte dos atores educacionais, incluindo alunos, professores/monitores e outros funcionários de prisões, mas, sobretudo, dos prisioneiros. Naquela ocasião, enquanto procedia à busca de informações de campo como procedimento metodológico para a pesquisa, cujos objetivos eram detectar as particularidades e singularidades dos processos educacionais no interior do cárcere, bem como questionar a noção amplamente disseminada de sistema prisional enquanto um conjunto monolítico de normas, procedimentos e padrões de condutas, observou-se, concomitante, essa característica funcional a todas as instituições mais fechadas e centralizadas: a busca por formas pessoais e subjetivas de fuga ao controle quase absoluto exigido nesses locais, como forma de sobrevivência do sujeito.

A pesquisa inicial de campo foi realizada em oito penitenciárias do estado de São Paulo, sendo duas localizadas na região de Guarulhos, três na região de Presidente Prudente, uma em Bauru, outra em Sorocaba e, finalmente, a última na região de Franco da Rocha, e demonstraram que as ações educacionais nos presídios são extremamente diferenciadas, porque sofrem uma variação considerável à medida que variam também a "equipe dirigente" e o corpo de funcionários ou "staff" de cada instituição. Nessas primeiras unidades prisionais observadas, foram entrevistados os diretores de educação, responsáveis pela política pública de EJA na instituição. Ao optarmos por duas delas para, à maneira do etnógrafo, "mergulhar" no interior das mesmas, acompanhamos por uma semana em cada instituição os "procedimentos ritualísticos" desenvolvidos nos processos educacionais para os prisioneiros. Com isso foi possível captar nuanças do ambiente do cárcere e dos sujeitos que o compõe, examinado as iniciativas escolares realizadas sob quatro variáveis de análise: tempo, espaço, organização e práticas escolares.

Nestas unidades prisionais, ampliamos os sujeitos submetidos às entrevistas, buscando um confronto maior de ideias e referências sobre a escola e os procedimentos escolares que nos permitissem acessar, justamente, as capilaridades do poder institucional-funcional e as tentativas, muitas vezes, frustradas e outras bem sucedidas, de resistência a esse poder representado pelas normas e regras rígidas de agir no interior do cárcere. As entrevistas que realizamos vieram acompanhadas de um levantamento prévio de informações pessoais relativas aos sujeitos entrevistados, especialmente dos 
A educação enclausurada: reflexões sobre autonomia relativa e os mecanismos de resistência à dominação na escola do cárcere

diretores Gerais, de Segurança e Disciplina, Reabilitação e Educação. Outro levantamento bastante específico foi obtido junto aos funcionários que tratam da segurança interna do presídio, neste caso, os Agentes de Segurança Penitenciária. Outro grupo eleito para ser entrevistado foi o dos monitores, fossem presos ou de "fora" da prisão, já que este grupo compunha, juntamente com os diretores das instituições prisionais, com os funcionários voltados à segurança e disciplina interna e os próprios sentenciados, os atores dos processos educacionais no interior dessas instituições. No percurso da pesquisa de campo, uma orientadora pedagógica que iniciava suas atividades nessa função numa das penitenciárias, e que soube de nossas intenções, ofereceu-se espontaneamente para a entrevista, o que nos foi de imensa surpresa. Sua entrevista revelou-nos fatos bastante esclarecedores.

Foram entrevistados uma única vez 23 sujeitos, sendo 11 numa Penitenciária e 12 na outra, sendo dois alunos, dois Agentes de Segurança Penitenciária, quatro diretores, dois monitores presos e uma coordenadora pedagógica na primeira instituição e três alunos, três Agentes de Segurança Penitenciária, quatro diretores e dois monitores educacionais, um deles cumprindo pena privativa de liberdade na unidade prisional investigada, na segunda. Não escolhemos a priori a maioria dos entrevistados; apenas transmitíamos aos sujeitos com que íamos mantendo contato nas instituições prisionais, a pretensão de realizar algumas entrevistas com um grupo pequeno de atores envolvidos com a escola na prisão, com exceção do grupo dirigente, esse sim, elencado previamente. Os sujeitos foram, assim, surgindo, na condição de voluntários para a coleta de dados.

Os estudiosos clássicos da prisão como Foucault e Goffman, bem como da escola, como Barroso, Apple, Nóvoa e Viñao Frago, orientaram aqueles estudos, entre outros pesquisadores que também se debateram, ou sobre a prisão e suas particularidades como instituição social destinada a conter pessoas condenadas pela justiça e, portanto, privadas de liberdade, ou sobre os processos educacionais que ocorrem em seu interior e que são considerados como política de assistência aos encarcerados. As conclusões indicaram, conforme as análises eram realizadas e os resultados surgiam, o quanto a escola no cárcere oferecia, mais que um ambiente "neutro" em relação aos demais locais de circulação de pessoas reclusas, uma arena profícua, onde as relações de poder e dominação podem e devem ser debatidas, confrontadas e, quiçá, sublevadas. 


\section{Autonomia (im) possível? Normatizações, espaços enclausurados e o embate da dimensão humana}

Deve-se considerar primeiramente que algumas mudanças bastante significativas ocorreram no interior da política educacional oferecida pelo poder público estatal às pessoas privadas de liberdade e encarceradas nas prisões de São Paulo, como por exemplo, a publicação do Decreto $\mathrm{n}^{\circ}$ 57.238, de 17 de agosto de 2011, que instituiu o Programa de Educação nas Prisões considerando o que preconizavam as "Diretrizes Nacionais para a oferta de Educação para Jovens e Adultos em situação de Privação de Liberdade nos Estabelecimentos Penais”, ou Parecer CNE/CEB n ${ }^{\circ}$ /2010, do Ministério da Educação (BRASIL, 2010) que, basicamente, ofereceu um roteiro mais claramente acentuado e orientado para a prática educativa no interior do cárcere, com definições mais claras de princípios e a delimitação de marcos normativos inexistentes até então, para a implantação, oferecimento e consolidação dessa política pública no âmbito do território brasileiro ${ }^{1}$.

Com o advento das "Diretrizes" (BRASIL, 2010), a oferta da modalidade educacional para as pessoas privadas de liberdade entra, definitivamente, para o rol das políticas públicas de Educação de Jovens e Adultos (EJA); de forma geral, sob a coordenação central do Ministério da Educação e de forma regional, das Secretarias estaduais de Educação. Apesar da importância representada pela legislação nacional e internacional em relação à educação nas prisões nas últimas décadas, deve-se considerar, entretanto, que pouco se alterou em relação ao que já era oferecido concernente a essa política pública, além dessa perspectiva mais recente que estabelece as obrigações e o papel de cada gestor da entidade federativa na sua efetivação.

É bastante elucidativo, por exemplo, que, ao se verificar o número de prisioneiros (ou percentual de) matriculados nas escolas do cárcere, encontrem-se normalmente números próximos de $10 \%$, em relação ao total de pessoas que cumprem sentenças em

\footnotetext{
${ }^{1}$ Deve-se considerar que as mudanças trazidas pelo parecer do Conselho Nacional de Educação seguem e ampliam diretrizes gerais previstas em marcos legais nacionais anteriormente promulgados, tais como a própria Constituição da República Federativa do Brasil (1989); a Lei de Execução Penal (Lei no 7.210, de 1984), nos artigos 17 a 21-A; a Lei de Diretrizes e Bases da Educação Nacional (Lei 9.394/96); os Programas Nacionais de Direitos Humanos (PNDH1/1996; PNDH2/2002 e PNDH3/2009); o Plano Nacional de Educação (Lei $n^{\circ} 10.172$, de 2001); a Resolução no 03, do Conselho Nacional de Política Criminal e Penitenciária, de 2009 e o Decreto 7.626 de 2011, além dos acordos internacionais em que o Brasil é signatário, como as "Regras Mínimas para o Tratamento de Pessoas Presas", de 1955, da Organização das Nações Unidas (ONU), nas regras 40, 77 e 78; os "Princípios Básicos Relativos ao Tratamento de Reclusos", também da ONU, de 1990; as e, finalmente, a Resolução 1990/20, do Conselho Econômico e Social das Nações Unidas, dentre outros.
} 
A educação enclausurada: reflexões sobre autonomia relativa e os mecanismos de resistência à dominação na escola do cárcere

prisões, sem variar significativamente nestes últimos dez anos, percentual que está abaixo do número de pessoas que se declararam analfabetas ou alfabetizadas, porém, sem comprovação de cursos regulares, na marca dos $15 \%{ }^{2}$. Em que pese o alcance limitado da política educacional para o cárcere, segundo informações oficiais do governo brasileiro disponíveis no Levantamento Nacional de Informações Penitenciárias (INFOPEN/2014), é fato que 38.831 prisioneiros estiveram envolvidos em atividades educacionais no cárcere em junho de 2014 , representando $10,7 \%$ do total de pessoas privadas de liberdade e em cumprimento de sentenças judiciais nas prisões brasileiras.

As estatísticas são ainda mais sinistras, quando se pensa a política de escolarização em instituições de detenção provisória, destinadas àquelas pessoas que ainda aguardam o andamento e a conclusão de seus processos penais. Dado o caráter provisório da sanção (que pode durar alguns anos!) e a particularidade dessas instituições (Centros de Detenção Provisória, Cadeias Públicas ou mesmo Delegacias de Polícia), não existem espaços adequados planejados para as assistências previstas em lei para as pessoas privadas de liberdade. Segundo dados do INFOPEN (2014), $41 \%$ de pessoas cumprindo essas medidas não teriam condenação à época do levantamento das informações nas unidades federativas; destas, $60 \%$ delas estavam custodiadas já há mais de 90 dias. Da totalidade de estabelecimentos penais existentes no Brasil, quase metade deles não dispunham de uma única sala de aula (48\%), evidenciando a situação caótica das políticas penais e penitenciárias. Todos esses números não deixam de ser significativos, principalmente pelo conjunto de relações interpessoais decorrentes dos processos de escolarização no interior das instituições prisionais que contam com essa assistência.

Michel Apple (1989) deixou-nos reflexões importantíssimas que se pretende aprofundar neste artigo, principalmente no que se refere às resistências encontradas naquelas relações estabelecidas nas escolas e que envolvem alunos, professores e outros funcionários, aqueles “elementos de contradição, de resistência, de autonomia relativa que tem potencial transformativo, (encontrados) em quase toda a situação real de trabalho" (APPLE, 1989, p. 102), na sociedade como um todo e nas escolas, em particular. Ambas as instituições que investigamos neste artigo, a prisão e a escola, devem merecer todos os nossos esforços analíticos na tentativa de não reduzir uma a outra, bem como não perder de vista que aquilo que se quer compreender aqui é a escola que funciona

\footnotetext{
${ }^{2}$ Disponível em: 〈http://www.justica.gov.br/seus-direitos/politica-penal/relatorio-depen-versao-web.pdf $>$. Acesso em: 19 fev. 2016.
} 
no interior das prisões, com suas nuances, particularidades e singularidades em relação às suas similares existentes no mundo dos homens livres.

Não é novidade que essas primeiras instituições, as prisões, buscam seguir um roteiro rigidamente estruturado para atingir seus objetivos, confessados ou não. Por outro lado, uma escola dentro da prisão, deve, em decorrência desta outra, ter a sua estrutura e a sua existência marcada pelo fato de estar funcionando ali, em algum canto ou recôndito da prisão; obedecer ao conjunto de normas mais gerais daquela e esquematizar as suas próprias regras e normas de funcionamento para a consecução da tarefa a que se propôs a partir do que está estabelecido de forma mais geral nas leis mais gerais e nos regulamentos disciplinares da prisão ${ }^{3}$. A nossa pergunta fundamental continua sendo "como essas duas instituições sociais se relacionam e interagem num primeiro momento, enquanto instâncias que têm propostas confessadas plenamente opostas, embora se consiga contradizer o que ambas têm a oferecer a seus internos?”. A suposição da investigação é a de que a prisão atua especificamente cerceando o sujeito que a ela é conduzido, em oposição à escola que, em tese, teria como finalidade ampliar o senso de percepção da realidade em seus educandos:

Se essas (as) normas e práticas relativamente autônomas e de resistência existem, onde, quando, e como, especificamente, elas podem terminar sendo contraditórias, talvez até mesmo reforçando, assim, os preceitos ideológicos e econômicos de forma ainda mais profunda? (APPLE, 1989, p. 100).

Ao mesmo tempo em que têm objetivos latentes opostos, as duas instituições, a prisão, esse “espaço entre dois mundos" (FOUCAULT, 1983, p. 109) e um "observatório permanente que permite distribuir as variedades do vício ou da fraqueza" (FOUCAULT, 1983, p. 112) e a escola também têm realidades que são consoantes; como exemplo, podese pensar no esquadrinhamento meticuloso do tempo e dos espaços (onde se possa fazer uma coisa específica num local previamente determinado), no controle dos comportamentos e dos pensamentos (numa "tecnologia política dos corpos"), nas tecnologias de poder e nos mecanismos institucionais, como já sugeriu Michel Foucault,

\footnotetext{
${ }^{3}$ A exemplo das prisões, que são locais de cumprimento de pena privativa de liberdade por adultos que cometem crimes, nas instituições para cumprimento de medida socioeducativa por adolescentes que cometem atos infracionais, como aquelas sob administração da Fundação Casa, em São Paulo, por exemplo, também são encontradas escolas em seu interior. Para as políticas desse campo, entretanto, seguem-se legislações específicas, como o Estatuto da Criança e do Adolescente (Lei $n^{\circ} 8.069$, de 1990), ou a Lei $n^{\circ}$ 12.594, de 2012, que institui o SINASE (Sistema Nacional de Atendimento Socioeducativo), ou mais gerais, como a própria LDB/1996 e a CF/1989. Para citar alguns autores com produção significativa acerca das políticas públicas implementadas nos espaços de restrição e privação de liberdade juvenil, indicam-se os trabalhos de Antonio Carlos Gomes da Costa, João Batista Costa Saraiva e Carlos Roberto Jamil Cury.
} 
A educação enclausurada: reflexões sobre autonomia relativa e os mecanismos de resistência à dominação na escola do cárcere

em várias de suas obras, mais especificamente em "Microfísica do Poder" (1979), "Vigiar e Punir" (1983) e "Estratégia Poder-Saber" (2006): "é verdade que as escolas se parecem um pouco com as prisões" (DELEUZE, in: FOUCAULT, 1979, p.73). A grande questão é como se pensa fora desses sistemas? Quais são as verdadeiras possibilidades ofertadas pela escola para que ocorra a emancipação, pensando-se como Theodor Adorno (1995), especialmente nos textos sobre a "Educação após Auschwitz" e "Educação e emancipação":

(...) A organização social em que vivemos continua sendo heterônoma, isto é, nenhuma pessoa pode existir na sociedade atual realmente conforme suas próprias determinações; enquanto isto ocorre, a sociedade forma as pessoas mediante inúmeros canais e instâncias mediadoras, de um modo tal que tudo absorvem e aceitam nos termos desta configuração heterônoma que se desviou de si mesma em sua consciência. É claro que isto chega até as instituições, até a discussão acerca da educação política e outras questões semelhantes. $\mathrm{O}$ problema propriamente dito da emancipação hoje é se e como a gente - e quem é "a gente", eis uma grande questão a mais - pode enfrentá-lo (ADORNO, 1995, p. 181-182).

Quando Barroso (1996, p. 186) fala em "autonomia construída” da escola, deixa claro que "não há autonomia da escola sem o reconhecimento da autonomia dos indivíduos que a compõem”. Aqui, parece concordar com Apple (1989, p. 170), quando apregoa que “(...) é na interação entre o conteúdo, a forma e a cultura vivida dos estudantes que as subjetividades são formadas. Nenhum elemento desse conjunto de relações pode ser ignorado". A tarefa a que nos propusemos naquela ocasião e que agora retomamos foi a de encontrar comportamentos, posturas, gestos, sinais e formas de comunicação dos sujeitos que frequentavam as salas de aula das escolas no interior das instituições prisionais e que nos indicassem que haveria, sim, possibilidades de resistência ao poder e de autonomia pessoal e coletiva, mesmo em instituições reguladas por normas e regras extremamente rígidas do ponto de vista de sua organização interna. Interessamonos por encontrar aquelas atitudes que pudessem servir como parâmetros para o resultado do jogo de forças que, inexorável e cotidianamente, ocorre no interior das escolas em instituições prisionais (punir versus ressocializar, ou como uma instituição marcadamente punitiva e castradora como a prisão pensa em propor a ressocialização das pessoas enclausuradas em seu interior; ou objetivos manifestos versus objetivos latentes, para dar apenas dois exemplos).

(...) A autonomia da escola não é a autonomia dos professores, ou a autonomia dos pais, ou a autonomia dos gestores. A autonomia, neste caso, é o resultado do equilíbrio de forças, numa determinada escola, entre diferentes detentores de influência (externa e interna), dos quais se destacam: o governo e os seus representantes, os professores, os alunos, os pais e outros membros da sociedade local (BARROSO, 1996, p. 186). 
Nas instituições de privação da liberdade como as prisões, as resistências dos encarcerados às normas, às regras e ao instituto de poder total, por parte dos dirigentes e dos outros funcionários, podem resultar num motim ou rebelião sem precedentes. A possibilidade de autonomia dos encarcerados em relação ao conjunto de regulamentos é, de alguma forma, negada e rechaçada a todo instante pelos detentores do poder institucional, principalmente porque "a prisão de segurança máxima, como qualquer organização, leva a marca particular dos homens no poder" (SYKES, 1999, p. 36) ${ }^{4}$. Mais importante que a participação dos sujeitos encarcerados nas rotinas institucionais é a sua pronta disponibilidade para acatar o regulamento:

(...) É o controle do comportamento dos prisioneiros que é enfatizado ao invés do controle da mente do prisioneiro, pela razão de que se as ações do indivíduo forem forçadas a combinar com as demandas normativas, a mente seguirá depois (SYKES, 1999, p. 37-38).

Sykes, em sua obra de 1958, fez um levantamento empírico da vida social de aproximadamente 1.200 prisioneiros, encarcerados numa prisão de segurança máxima de New Jersey, Estados Unidos da América. Já naquela ocasião, em que pesasse a constatação de que estavam os internos submetidos à rígida disciplina da prisão, foi possível, por intermédio do olhar criterioso do cientista, perceber que em meio a essa intensa e forçada submissão às normas e à perda da autonomia individual, focos de resistência podiam se destacar das profundezas da instituição: "ofensas cometidas por um recluso contra o outro, como ofensas cometidas por reclusos contra os funcionários e suas regras” (SYKES, 1999, p. 42-43), ou ainda “(...) apatia, sabotagem e a exibição de proeza ao invés da substância - as respostas tradicionais do escravo - surgem na prisão para incomodar o gerente-administrador e seus limitados meios de coerção não podem evitar ocorrer (SYKES, 1999, p. 28).

Sykes também percebeu que, mesmo aqueles funcionários que detinham autoridade e a possibilidade de punição ao simples desrespeito à norma, não as detinham constante e continuamente. A convivência e o relacionamento prolongado entre prisioneiros e funcionários de prisões, a corrupção, o fato de que "guardas e prisioneiros são tirados da mesma cultura e mantêm muitos dos mesmos valores e crenças" (1999, p. 33), e ainda o fato de que “(...) a ordem não emitida, a desobediência deliberadamente

\footnotetext{
${ }^{4}$ O livro de Greesham Sykes aqui mencionado ainda não possui tradução para o Brasil. A tradução para este trabalho, portanto, é livre.
} 
A educação enclausurada: reflexões sobre autonomia relativa e os mecanismos de resistência à dominação na escola do cárcere

ignorada, o dever deixado de ser executado - estes são rachaduras no monólito justamente tão certamente como são os atos de desafio na população objeto" (SYKES, 1999, p. 53). Em outro trabalho que fizemos sobre aspectos do espaço de vida ${ }^{5}$ no interior das prisões, já havíamos alertado para o fato de que alguns dos movimentos de resistência ao conjunto de normas instituídas pela burocracia estatal e de solidariedade encontrados nos profissionais entre si, entre profissionais e prisioneiros e entre prisioneiros entre si, visariam a própria possibilidade de existência, tanto no interior dessas instituições austeras e inflexíveis como fora delas (LOURENÇO, 2011).

Em seu estudo, Sykes (1999) pouco trata da escola ou dos processos de escolarização efetuados no interior daquela "prisão de segurança máxima" que estudou, até porque não era esse tema, especificamente, que lhe interessava enquanto pesquisador. Entretanto, é possível que os mesmos mecanismos, usados pelos prisioneiros de confrontação das normas, das regras e do poder exercido pelos funcionários no interior do cárcere, sejam encontrados no interior das escolas das prisões, inclusive de forma mais explícita, dada a peculiaridade do espaço escolar, normalmente entendido como de exposição do que as pessoas pensam sobre a realidade que as cercam.

Nos trabalhos que orientaram a nossa primeira pesquisa, em 2005, ora o espaço escolar era visto como local privilegiado em relação aos outros locais de convivência e de circulação dos encarcerados (ONOFRE, 2002; LEME, 2002; LEITE, 1997; SANTOS, 2002; GOIFMAN, 1998), ora era um local privilegiado por deter normas e regras de funcionamento diferenciadas e mais flexíveis do que as normas gerais, bem como valores também diferenciados em relação aos valores institucionais (ONOFRE, 2002; LEITE, 1997). Ora esse local era investigado a partir do olhar dos monitores presos e a partir de sua formação para a docência (PENNA, 2003), ora ainda como um importante local de disputa e preservação de direitos humanos fundamentais (GRACIANO, 2005) e onde a participação da sociedade civil organizada seria fundamental.

A grande concorrência existente nas prisões entre as políticas de trabalho (laborterapia) e de escolarização dos prisioneiros, bem como a resistência do corpo funcional responsável pela segurança da instituição à implementação efetiva dessas políticas é o tema do trabalho de mestrado de Português (2001). Para ele, refletindo as

\footnotetext{
${ }^{5}$ O espaço de vida é um conceito de Kurt Lewin (1975), que compreende a totalidade dos fatos que determinam o comportamento de um indivíduo num determinado momento, representando a totalidade dos eventos possíveis.
} 
ideias de Michel Foucault (1983) sobre os três grandes princípios da reabilitação dos prisioneiros, o isolamento, o trabalho penitenciário e a autonomia da gestão penitenciária existiria um conceito principal permeando as políticas e as atividades existentes nas prisões:

No cerne do conceito de reabilitação penal, encontra-se a tarefa de transformar indivíduos criminosos em não criminosos. É ao que se propõe a prisão - sua terapêutica - mediante a participação (voluntária) dos apenados nos programas que dispõem, a concordância em seguir normas, regras e procedimentos, principalmente disciplinares, a fim de obter aquela recompensa, aquele direito: a reabilitação (PORTUGUÊS, 2001, p. 78).

Português (2001) conclui que a partir dessa proposta de se transformar os indivíduos criminosos em não criminosos, desencadeada pela operação penitenciária e fundada nos três grandes princípios elencados acima - isolamento, trabalho penitenciário e gestão penitenciária, "tornou-se possível a edificação de um saber técnico - científico sobre os indivíduos, declinando o foco de ação do crime, para aquele que o cometeu. $\mathrm{O}$ indivíduo é o foco central do trabalho penitenciário, não o seu ato" (p. 79). Seja como for, é possível supor que o "clima organizacional" originado e mantido nas escolas das instituições prisionais contribua para essas percepções dos sujeitos que frequentam esses locais destinados ao ensino e aprendizagem, apesar da imposição vertical e hierarquizada das normas pela "equipe dirigente" e pelo corpo de funcionários nessas instituições de “equilíbrio precário" (COELHO, 1987).

O que temos em mente, então, é que na confluência de interrrelações desenvolvidas por monitores/professores ${ }^{6}$, alunos, supervisores, funcionários, entre outros, com as características físicas instituídas para as escolas nas instituições prisionais, reside uma possibilidade de diferenciação dos sujeitos que ali se encontram. Para nós, num ambiente mais favorável, onde as relações entre as pessoas possam fluir com maior naturalidade e menor rigor, a "autonomia construída" dos sujeitos pode ser majorada quando comparada com aquela autonomia de sujeitos mantidos em condições menos favoráveis e em espaços menos flexíveis. Muito embora não seja nossa pretensão

\footnotetext{
${ }^{6}$ Até a publicação das "Diretrizes Nacionais para a oferta de Educação para Jovens e Adultos em situação de Privação de Liberdade nos Estabelecimentos Penais" (BRASIL, 2010), era possível encontrar nas unidades penais do estado de São Paulo, pelo menos, a figura dos "monitores presos", ou seja, aqueles sujeitos que, tendo uma formação educacional e cultural um pouco superior à média da população reclusa, passavam a ensinar aos colegas regularmente matriculados nas escolas dos cárceres; estes monitores presos eram contratados pela FUNAP (Fundação Manoel Pedro Pimentel), instância prevista na organização administrativa da SAP (Secretaria de Administração Penitenciária do estado de São Paulo) responsável pela aplicabilidade da política pública de educação e trabalho às pessoas privadas de liberdade e encarceradas nas prisões do estado.
} 
A educação enclausurada: reflexões sobre autonomia relativa e os mecanismos de resistência à dominação na escola do cárcere

“calcular" o grau de eficácia comparativa entre duas escolas, cabe-nos aqui citar novamente Barroso (1996), numa menção a Good \& Weinstein (in NÓVOA, 1992), que “(...) existe uma variação significativa entre as escolas, no que se refere aos resultados escolares obtidos pelos alunos, bem como com a existência de um sem número de características próprias das escolas eficazes" (GOOD \& WEINSTEIN apud BARROSO, 1996, p. 179).

Estão em jogo, portanto, singularidades muito importantes quando realizamos o tipo de comparação entre dois ou mais espaços e formas escolares a fim de levantarmos as resistências e as autonomias encontradas ${ }^{7}$. A estruturação daqueles espaços delimitados para as práticas educativas é uma dessas singularidades, podendo ter relação direta com o tipo de atividade que se faz ali. Assim, imaginamos fazer muita diferença, por exemplo, frequientar aulas em típicas salas de aula, onde as portas, embora encostadas a fim de evitar interrupções desnecessárias, estão destrancadas e são de matéria prima similar às de nossas escolas da vida livre - a madeira, e "celas de aula" (LEME, 2002), espaços destinados ao ensino e a aprendizagem trancados a cadeado a cada entrada e saída de alunos e contendo chapas de aço e grades de ferro como portas, além de excessiva e rigidamente vigiados.

A administração própria aos espaços escolares é outra característica que pode fazer a diferença para os alunos que freqüentam as escolas, quando temos em mente que cada escola é diferente em seu núcleo, ou “(...) Se há uma organização administrativa igual para todas as escolas de determinado tipo, pode-se dizer que cada uma delas é diferente de outra, por apresentar características devidas à sua sociabilidade própria (CÂNDIDO, 1956, p. 107)". As escolas das unidades prisionais visitadas por ocasião daquela pesquisa original, em 2005, podiam variar a partir da própria configuração, também variável das instituições que as alojavam, mais antigas ou mais novas; destinadas a presos cumprindo suas sentenças em regime fechado ou em regime semiaberto; para presos de origem brasileira ou de origem estrangeira, como da posição ocupada em relação aos outros espaços de circulação, como por exemplo, anexa à instituição ou em algum recôndito da prisão, como ainda em relação ao uso, mais geral ou mais restrito (para todos os habitantes dos pavilhões ou para um ou outro pavilhão, especificamente).

\footnotetext{
7 Inicialmente foram visitadas oito unidades prisionais no estado de São Paulo a fim de orientar a escolha pelas duas delas que seriam objeto de nossa pesquisa em 2005. Naquele trabalho estão descritas com detalhes as observações de campo realizadas nessas duas. Para efeito deste artigo, no entanto, procurou-se rever as oito experiências anteriores.
} 


\section{A autonomia construída: as relações de poder e as possibilidades de emancipação}

Professores, monitores, supervisores escolares, enfim, os funcionários das escolas também podem contribuir para o sucesso ou o insucesso das práticas escolares e para o incremento ou não da autonomia produzida com seus alunos. Uma política educacional voltada para a qualificação de seu corpo de funcionários, para a possibilidade de apreensão de seu papel fundamental na trama dos processos educativos, na perspectiva de encarar os alunos também como sujeitos ativos no processo educacional e como portadores de uma história e de uma verdade que há de ser considerada, são vetores importantes a ser levados em conta, conforme argumenta Canário (1998), sustentando o que disseram Lesne \& Mynvielle (1990): “(...) a formação, como processo organizado e intencional, corresponde a um aspecto particular de um processo contínuo e multiforme de socialização que coincide com a trajetória profissional de cada um (LESNE \& MYNVIELLE, apud CANÁRIO, 1998, p.10)".

Outra questão que nos diz respeito é a possibilidade de se encontrar diferenças significativas nas concepções e crenças pessoais entre os sujeitos que frequentam as escolas das instituições prisionais, além da sua interação na turma ou sala de aula:

(...) Contrariamente ao que se julgava, os efeitos da escola (enquanto organização) não podem ser dissociados dos efeitos da turma e do professor, uma vez que a maior parte dos estudos mais recentes que utilizam métodos de multivariáveis mostram que a maior parte das diferenças entre as escolas se devem a variações que se passam ao nível das turmas (BARROSO, 1996, p. 180).

Enfim, o questionamento pessoal do próprio lugar que ocupamos na sociedade e no mundo, de uma forma geral, bem como o questionamento das ações e das disciplinas dos homens de uma forma específica, deve ser levado em conta quando pensamos nas relações que se estabelecem nas escolas, principalmente quando elas (disciplinadoras por excelência!) se encontram instaladas no interior de instituições também disciplinadoras como as prisões. Aqui, Apple (1989, p. 112) é de grande ajuda, já que percebeu, mesmo entre os estudantes destinados socialmente à classe operária da economia americana, mecanismos algumas vezes bastante sutis de resistência e autonomia, frente à submissão desejada: 
A educação enclausurada: reflexões sobre autonomia relativa e os mecanismos de resistência à dominação na escola do cárcere

(...) Os estudantes tornam-se bastante hábeis em driblar o sistema. Grande número deles nas escolas urbanas de áreas pobres, isto para não falar de outras áreas, adaptam, de forma criativa seus ambientes, de forma que possam fumar, sair da aula, colocar humor em suas rotinas, controlar informalmente a cadência da vida escolar e, de forma geral, tentar levar o dia. (...) Além disso, o ensino velado de pontualidade, asseio, obediência e outras normas e valores de raiz mais econômica, é simplesmente repudiado tanto quando possível. A verdadeira tarefa dos alunos é a de sobreviver até que o sinal soe.

Lembramo-nos ainda de Philippe Perrenoud, quando, no Ofício de aluno (1995), uma obra em que o autor trata exaustivamente da dura lida da condição de estudante e faz referência a algumas características destes que são compartilhadas com outros grupos sociais, bastante necessárias para a sobrevivência destes todos:

Os alunos partilham - com os prisioneiros, os militares, alguns indivíduos internados ou os trabalhadores mais desqualificados - a condição daqueles que não têm, para se defenderem contra o poder da instituição e dos seus chefes directos, mais nenhuns outros meios que não sejam a astúcia, a subserviência, o fingimento. Pensar, antes de mais, em ultrapassar a situação, em adoptar as estratégias que garantam a sobrevivência e uma certa tranqüilidade, é humano (PERRENOUD, 1995, p. 17. Itálicos nossos).

Parece-nos ser improvável pesquisar a bibliografia disponível sobre os estudos a respeito das instituições prisionais sem encontrar indicações que apontem para certa "autonomia" daqueles sujeitos que, cotidianamente, estão envolvidos na administração de uma instituição desse tipo. Essa autonomia é verificada quando se contrasta as ações e as práticas da "Equipe Dirigente" e do corpo de funcionários com os instrumentos que deveriam nortear as condutas mais gerais no interior dessas "organizações complexas" (FISCHER, 1989).

Erwing Goffman, com o seu estudo sobre os "Manicômios, Prisões, Conventos", originariamente publicado em 1961, é o autor que inaugura a discussão sobre os paradoxos e as contradições inerentes à prática no interior das "instituições totais", marcadas que são por um conjunto de características próprias às mesmas que as diferenciariam das demais instituições da sociedade organizada. Da mesma forma, Goffman também percebeu, depois do estudo de campo que empreendeu num grande Hospital em Washington, DC, que "mundo do internado" e "mundo da Equipe Dirigente" são dois mundos bastante peculiares e diferenciados entre si, cujas dinâmicas possuem vida própria. Não foi do interesse desse autor centrar-se no mundo da Equipe Dirigente, entretanto, nos trouxe ele, com seus estudos, importantes contribuições para se entender a forma como se estabelecem as relações subjetivas no interior de instituições totais.

Uma das primeiras contribuições de Goffman (1987) quando trata da "equipe dirigente" nas "instituições totais" é a advertência de que a matéria prima por excelência 
que é trabalhada nessas instituições é o ser humano, diferentemente da matéria prima das fábricas, dos escritórios e de outros locais de atividade produtiva, onde o objeto a ser "melhorado" ou transformado é inanimado. Aliás, em que pese essa diferenciação, é importante lembrar que esse caráter de inanimado pode ser adquirido pelos sujeitos internados em instituições totais, segundo o autor: "como material de trabalho, as pessoas podem adquirir características de objetos inanimados" (GOFFMAN, 1987, p. 70). Ao contrário da lida com substâncias inanimadas, "os maus tratos em objetos inanimados podem deixar marcas visíveis para os supervisores" (GOFFMAN, 1987, p. 70).

Da mesma forma, o processo de produção pedagógica é incomparavelmente diferente do processo de produção de qualquer objeto; assim sendo, é bastante improvável a transformação das escolas em fábricas ou oficinas, apesar das possíveis semelhanças ou similaridades encontradas também nessas duas instituições. A matéria prima das primeiras, os estudantes, faz parte integrante do processo produtivo e, sem a participação (ativa), não há processo pedagógico. Os professores, considerados os "proletários do ofício", não podem ser expropriados do seu instrumento de produção (o saber). Não é possível, portanto, mensuração exata do quanto se aprendeu, apesar das inúmeras provas e testes criados para isso, já que existem aprendizados que se prolongam pela vida.

\begin{abstract}
A administração escolar precisa saber buscar na natureza própria da escola e dos objetivos que ela persegue os princípios, métodos e técnicas adequados ao incremento de sua racionalidade. (...) Uma administração escolar que pretenda promover a racionalização das atividades no interior da escola deve começar, portanto, por examinar a própria especificidade do processo de trabalho que aí tem lugar (PARO, 2000, p. 136).
\end{abstract}

Uma segunda característica que irão encontrar aqueles que trabalham nas instituições elencadas por Goffman é que "os internados geralmente tem status e relações no mundo externo, e isso precisa ser considerado" (GOFFMAN, 1987, p. 71). Essa contradição entre a possibilidade de usufruir da matéria prima, ou do "corpo do internado" a seu bel prazer e a possibilidade de ver descoberto um "erro", uma "alteração", um "descuido" ou uma "negligência" qualquer por outros membros de dentro da instituição (supervisores, gerentes ou pares) e mesmo de "fora" (parentes, amigos, autoridades) que acabam "fiscalizando" o trabalho desenvolvido, se refere, segundo o autor, a "dilemas clássicos que precisam ser enfrentados por aqueles que governam os homens" (GOFFMAN, 1987, p. 72).

Resulta daí que muitas das decisões que são tomadas e mesmo muitas das ações que são desenvolvidas no dia a dia de uma instituição total acabam escamoteadas, omitidas ou mesmo "escondidas" do grupo de internados e mesmo da própria sociedade, 
A educação enclausurada: reflexões sobre autonomia relativa e os mecanismos de resistência à dominação na escola do cárcere

graças a um espírito de corpo ou de equipe desenvolvido pelo conjunto de trabalhadores nessas instituições. Esse espírito de corpo surge como barreira pessoal e organizacional contra a possibilidade frequente de críticas à postura e à atividade profissional no interior das instituições prisionais:

(...) As pessoas da direção que estão em contato direto com os internados podem pensar que também elas estão diante de uma tarefa contraditória, pois precisam impor obediência aos internados e, ao mesmo tempo, dar a impressão de que os padrões humanitários estão sendo mantidos e os objetivos racionais da instituição estão sendo realizados (GOFFMAN, 1987, p. 84).

Michel Foucault é outro autor que vem ao nosso auxílio e, de certa forma, amplifica o nosso olhar em relação às instituições prisionais, com os conceitos de disciplina e poder. Em seu livro "Microfísica do Poder" (2003), encontramos uma análise brilhante de como o poder pode ser encontrado mesmo nos espaços e nos sujeitos que imaginamos, encontram-se destituídos de poder. Segundo Foucault, imperaria nas sociedades humanas uma rede indestrutível de "poderes", que navegariam indistintamente por entre as diversas tarefas da vida dos sujeitos, regulando-os e sujeitando-os. A investidura desses poderes na vida humana se daria, segundo Roberto Machado que organiza, interpreta e revisa o original de Foucault, através de "dispositivos ou mecanismos que a nada ou ninguém escapa, a que não existe exterior possível, limites ou fronteiras" (MACHADO, 2003, p. XIV). Um desses mecanismos disciplinares, e talvez o mais conhecido para os estudiosos das prisões, é o Panopticon, de Jeremy Bentham, que é descrito assim por Foucault (2003, p. 210):

O princípio é: na periferia, uma construção em anel; no centro, uma torre; esta possui grandes janelas que se abrem para a parte interior do anel. A construção periférica é dividida em celas, cada uma ocupando toda a largura da construção. Estas celas têm duas janelas: uma abrindo-se para o interior, correspondendo às janelas da torre; outra, dando para o exterior, permite que a luz atravesse a cela de um lado a outro. Basta então colocar um vigia na torre central e em cada cela trancafiar um louco, um doente, um condenado, um operário ou um estudante. Devido ao efeito de contraluz, pode-se perceber da torre, recortando-se na luminosidade, as pequenas silhuetas prisioneiras nas celas da periferia. Em suma, inverte-se o princípio da masmorra: a luz e o olhar de um vigia captam melhor que o escuro que, no fundo, o protegia.

Mecanismos como o Panóptico, de Bentham, estariam disseminados pela nossa sociedade, bem como pelas disciplinas humanas, segundo Foucault. Seja na concepção de um projeto arquitetônico de prisão, hospital, fábrica ou mesmo escola, seja na antítese do "sonho rousseauniano presente em tantos revolucionários" (FOUCAULT, 2003, p. 215) que ousaram imaginar uma sociedade de iguais e acabaram por encontrar uma sociedade onde a visibilidade organizada gira "em torno de um olhar dominador e 
vigilante" (FOUCAULT, 2003, p. 215). Assim, a consecução dos objetivos concretos da prisão, por suas características de fechamento e isolamento do restante da sociedade, passaria pela utilização de todo um conjunto de dispositivos ${ }^{8}$ e mecanismos disciplinares e disciplinadores por parte dos detentores do poder de decisão nesses estabelecimentos, entre eles, a equipe dirigente e o corpo de funcionários. A utilização do poder por parte dessas pessoas ser-lhes-ia, de certa forma, irresistível.

A autonomia explícita de que se valem os funcionários das prisões no desenvolvimento de suas atividades é destacada pela maioria, se não, a totalidade dos autores com os quais aqui dialogamos. Para Sérgio Adorno (1991, p. 26), por exemplo, essa é uma "autonomia no sentido perverso. Cada agência funciona segundo critérios extremamente próprios, para o que não deve prestar conta a ninguém nem a nada". Em outro de seus escritos, esse autor reclama do que seria um poder ilimitado por parte dos diretores penais: “(...) não há o que possa contê-los, sobretudo quando adotam medidas, muitas vezes arbitrárias, em nome da preservação da segurança e da disciplina do sistema penitenciário" (ADORNO, 1991, p. 32).

Fernando Salla (1994, p. 95) defende que se desvinculem os processos educacionais desenvolvidos nas instituições prisionais da lógica intrínseca à mesma, de forma que: “(...) haveria absoluta necessidade de se desvincular todo e qualquer tratamento, qualquer programa de atividades para presos do esquema disciplinar das prisões”. Paixão (1985, p.101), também nos chama a atenção para essa questão quando diz que “(...) nas penitenciárias, os internos experimentam não apenas o arbítrio de guardas e administradores despreparados, quando não hostis e punitivos, mas também a exposição a uma forma peculiar de organização social”. Leme $(2002$, p. 118) também encontra essas práticas arbitrárias interferindo nos processos educacionais na prisão por ele estudada:

A escola - e como conseqüência a educação escolar, nosso objeto de estudo é tratada na maioria das vezes pelos funcionários como um lugar secundário, não dão valor, acreditam que o preso não precisa estudar - "malandro só procura a escola depois que vai preso". Quando podem, dificultam o acesso dos alunos presos, até a sala de aula. Mesmo por motivos banais, podem de forma definitiva impedir que o aluno estude, interagem de forma negativa na avaliação do ex-aluno, dificultando dessa forma, a obtenção de um benefício.

\footnotetext{
8 Por dispositivo, Foucault (2003, p. 244) entende "a rede que se pode estabelecer entre estes elementos (o dito e o não dito)". Haveria não só uma distância enorme entre as coisas que são ditas e as coisas que não são ditas pelos sujeitos, como também uma relação direta entre as mesmas, com o fim de manter um padrão de existência social homogêneo e de criação e manutenção de homogeneidades.
} 
A educação enclausurada: reflexões sobre autonomia relativa e os mecanismos de resistência à dominação na escola do cárcere

Concordar com as afirmações acima não significa desconsiderar que existam verdadeiras "ilhas" (GOFFMAN) de autonomia naqueles sujeitos "dominados". O próprio Foucault (2003) reconhecia que contra o poder disseminado e disseminador existiriam possibilidade de resistência por parte daqueles que foram sujeitados. As resistências surgiriam em relances de imaginação e criatividade, mecanismos tipicamente humanos. Assim como vemos possibilidades de resistências individuais à dominação e à sujeição social, entendemos que é perfeitamente aceitável a tese de que, também, algumas organizações possuem certo grau de autonomia frente a outras, ou em contraposição a outras. Deve-se

(...) compreender esa doble naturaleza de la escuela como institución social condicionada y condicionante de la realidad social externa a ella, como uma institución relativamente autónoma que genera una cultura específica, unas prácticas determinadas de transmisión y mediación cultural adoptadas posteriormente por otras instituciones o actores sociales y aceptadas como los únicos o las más adecuados modos de enseñanza y aprendizaje, de evaluación y acreditación (VIÑAO FRAGO, 2000, p. 109).

\section{Considerações finais}

Um pequeno bilhete contendo um pedido para que o observador (ou mesmo o professor presente na sala de aula) contate um familiar distante e lhe diga que "fulano está bem", entregue naquele momento em que a vigilância "baixa a guarda", pode muito bem se encaixar nesse tipo peculiar e característico de resistência e afrontamento às normas existentes, apesar da simplicidade do gesto. Nessas instituições austeras, onde uma simples manifestação de carinho e amizade entre pessoas que convivem dia-a-dia é normalmente evitada, observar homens se beijando no rosto quando se reencontram a caminho das aulas pode ser encarado como o surgimento de uma ilha de solidariedade, conforto e humanidade num oceano de águas turbulentas.

A destruição do prédio escolar quando de uma rebelião é outro desses rompantes que combinam o não conformismo e a resistência ao poder totalitário com a mensagem clara aos dirigentes prisionais, de forma específica e para a sociedade, de forma geral, de que a política pública, da forma como estruturada, não pode dar certo. Foi isso o que aconteceu numa das duas unidades prisionais investigadas por ocasião da pesquisa que reelaboramos neste artigo, apesar de eventos similares e quase simultâneos ocorridos em ambas; numa delas, a que acreditávamos ter verificado componentes de flexibilização da vida no cárcere incluindo, ali, a existência dinâmica no interior do espaço escolar, apesar 
do motim, a escola enquanto aparelho composto de salas de aula, biblioteca e sala de professores foi mantida intacta; noutra, a que encontramos elementos que nos indicavam maior rigidez na aplicação da norma e menor possibilidade manifesta de expressão das subjetividades, nem o espaço escolar com toda a sua estrutura e os seus equipamentos necessários escapou da destruição levada à cabo com a rebelião ocorrida9 .

(...) À exemplo do que sucede com a materia-prima no ámbito da produção material, o aluno não sai do processo educativo como era quando aí entrou. No processo de produção material, a materia-prima é transformada com vistas à constituição do produto final, e, na condição de objeto de trabalho, participa do processo produtivo, opondo resistência e ao mesmo tempo sendo modificada pela ação transformadora do trabalho humano. Enquanto objeto da educação, o aluno assume também esse caráter de materia-prima (PARO, 2000, p. 141-142).

Há que se considerar, para fins deste artigo e da linha de pensamento que vimos perseguindo, que não necessariamente a resistência ao poder instituído e à dominação exercida sobre o conjunto dos prisioneiros, como a insubmissão temporária à dura vida no cárcere foram fatores decorrentes da escolarização pura e simplesmente ou da mera frequência às salas de aula existentes no interior da instituição; vimos, justamente no prédio escolar, aquelas manifestações de carinho, solidariedade, calma e humanidade que não vemos normalmente em outros locais de circulação dos prisioneiros, com exceção, talvez, daqueles locais de convivência mais íntima como são os pavilhões de moradia destes. Há que se acreditar num certo poder delimitador da escola e desses processos de escolarização que elevam o potencial discursivo e reflexivo dos estudantes, mesmo em locais de confinamento quase absoluto como as prisões. Influenciados por uma pedagogia libertadora, como desejava Paulo Freire, aposta-se "que a educação pode fazer alguma coisa em qualquer espaço, incluindo espaços repressivos, como é o caso das prisões" (ONOFRE, 2002, p. 24). Essas escolas seriam "as mediadoras entre saberes, culturas e a

\footnotetext{
9 A informação de que o prédio escolar fora completamente destruído na rebelião numa dessas unidades prisionais fora conseguida por meio de contatos com funcionários da própria penitenciária localizada no interior do estado de São Paulo, momentos depois do movimento de amotinamento dos prisioneiros e do retorno destes a sua rotina habitual. Da outra Penitenciária, localizada na Grande São Paulo e onde o prédio escolar fora poupado apesar da destruição de outros locais de circulação dos prisioneiros quando da rebelião, as informações são deste pesquisador, que trabalhava na instituição à época do evento, que também foi carregado de grandes tensionamentos, morte de prisioneiros e quebradeira em outros locais de circulação na instituição. Informações sobre essas rebeliões podem ser conseguidas na internet, em <http://noticias.uol.com.br/ultnot/reuters/2005/06/14/ult27u49481.jhtm>, acesso em 17 fev. 2016 e em: <http://www2.senado.leg.br/bdsf/bitstream/handle/id/312533/noticia.htm? sequence=1>, por exemplo. É importante observar que uma das rebeliões deu-se em 14 de junho de 2005 e a outra em 18 de outubro do mesmo ano, uma diferença de pouco mais de quatro meses.
} 
A educação enclausurada: reflexões sobre autonomia relativa e os mecanismos de resistência à dominação na escola do cárcere

realidade, oferecendo possibilidades que, ao mesmo tempo, libertem e unam os excluídos que vivem no interior das unidades prisionais" (ONOFRE, 2002, p. 06).

É patrimônio inalienável dessas escolas a mobilidade em seu interior, ou naqueles momentos que antecedem o ingresso dos alunos nas suas dependências ou ainda, quando delas saem. Ao contrário, as escolas do mundo prisioneiro e os processos de escolarização levados a cabo no interior do cárcere obedecem a esquemas bastante rígidos de disciplina e estabelecem rituais visando à impossibilidade de ocorrências que a desestabilizem e ao presídio. Em escolas rígidas, fechadas e altamente disciplinadoras como essas, onde até o leve murmúrio pode trazer represálias a algum aluno, e onde as relações se pautam antes pela desconfiança generalizada do outro, falar em sociabilidade parece fora de cogitação. Presenciamos atitudes de cordialidade, de respeito e de ternura muito mais naquela penitenciária onde as relações internas estabelecidas no interior do recinto escolar estavam mais flexibilizadas. Na penitenciária cujas aulas eram ministradas em verdadeiras "celas de aula", aos alunos restava trocar informações e confidências com os colegas nos intervalos regulares entre a própria entrada dos alunos e a chegada posterior dos monitores, ou na saída destes ao final das aulas até a abertura das "celas", pelos funcionários de plantão, ao final das aulas. Seja como for, parece consenso entre os alunos, tanto de uma penitenciária, quanto da outra que, além dos portões, gradeados ou não, da escola, muitas grades ainda os esperam, cerceando qualquer possibilidade de ser e estar livre. Alguns alunos chegavam a transformar em devaneios os momentos em sala de aula: olhavam distante através das grades das janelas, como se pudessem alcançar as muralhas que os cercavam e respirar, libertos, o ar sem vícios da liberdade.

Seja como for, os resultados aqui enunciados e discutidos indicam que ainda se carece de estudos empíricos mais sistemáticos que consigam garantir uma visão ampliada do alcance e da importância das políticas educacionais no interior do cárcere para as pessoas que delas se utilizam. Esse pequeno reduto de liberdade entre as grades, que tem como um de seus objetivos possibilitar níveis mais elevados de desenvolvimento cultural e maior autonomia dos sujeitos tem mostrado a potencialidade necessária para ser alçado, conforme a letra da lei já reconhece há tempos, a uma política pública, estatal e universal que contemple a possibilidade de distribuir o conhecimento técnico-científico, cultural e humanitário acumulado ao longo da história ao maior número possível de pessoas, mesmo que estas estejam, provisoriamente, em condições de privação ou restrição de liberdade. 


\section{REFERÊNCIAS BIBLIOGRÁFICAS}

ADORNO, S. Sistema penitenciário no Brasil: Problemas e desafios. Revista USP, São Paulo, v. 0, mar/maio, 1991, pp. 65-78.

ADORNO, T. W. Educação e Emancipação. Tradução Wolfgang Leo Maar. Rio de Janeiro: Paz e Terra, 1995.

APPLE, M. W. Educação e poder. Tradutora: Maria Cristina Monteiro. Porto Alegre: Artes Médicas, 1989.

BARROSO, J. (org.) O estudo da escola. Colab. Licínio C. Lima. Portugal: Porto Editora, 1996.

BRASIL. Ministério da Educação. Conselho Nacional de Educação. Diretrizes Nacionais para a oferta de educação para jovens e adultos em situação de privação de liberdade nos estabelecimentos penais. Parecer CNE/CEB no: 4/2010. Disponível em: $<$ http://portal.mec.gov.br/index.php?option=com_docman\&view=download\&alias $=444$ 5-pceb004-10\&category_slug=abril-2010-pdf\&Itemid=30192>. Acesso em: $17 \mathrm{fev}$. 2016.

CANÁRIO, R. A escola: o lugar onde os professores aprendem. Psicologia da Educação. São Paulo, 6, $1^{\circ}$ semestre, 1998, pp. 9-27.

CÂNDIDO, A. Separata de Educação e Ciências. Boletim do Centro Brasileiro de Pesquisas Educacionais. Rio de Janeiro, 1956, pp.107-128.

COELHO, E. C. A oficina do diabo: crise e conflitos no Sistema Penitenciário do Rio de Janeiro. Rio de Janeiro: Espaço e Tempo: Instituto Universitário de Pesquisas do Rio de Janeiro - UPERJ, 1987.

FISCHER, R. M. Poder e cultura em organizações penitenciárias. Tese de Livre Docência. Faculdade de Economia e Administração da Universidade de São Paulo USP, 1989.

FOUCAULT, M. Microfísica do poder. Organização, Introdução e Revisão Técnica: Roberto Machado. 24. ${ }^{a}$ Edição. São Paulo: Edições Graal, 1979.

. Vigiar e Punir. Nascimento da prisão. Tradução de Lígia M. Pondé Vassallo. 2a Edição. Petrópolis: Vozes, 1983.

Estratégia, Poder-Saber. Organização e seleção de textos: Manoel Barros da Motta. Tradução de Vera Lúcia Avelar Ribeiro. $2^{a}$ Edição. Rio de Janeiro: Forense Universitária, 2006 (Coleção Ditos e Escritos, volume IV).

GOFFMAN, E. Manicômios, Prisões e Conventos. Tradutor: Dante Moreira Leite. $5^{\mathrm{a}}$ Edição. São Paulo: Editora Perspectiva, 1987.

GOIFMAN, K. Valetes em Slow Motion - a morte do tempo na prisão. Campinas: Editora da Universidade de Campinas - UNICAMP, 1998. 
A educação enclausurada: reflexões sobre autonomia relativa e os mecanismos de resistência à dominação na escola do cárcere

GOOD, T. L. \& WEINSTEIN, R. S. As escolas marcam a diferença: evidências, críticas e novas perspectivas. In: NÓVOA, A. (org.) As organizações escolares em análise. Lisboa: Dom Quixote, 1992, p. 77-98.

GRACIANO, M. A educação como direito humano - a escola na prisão. Dissertação de Mestrado em Educação. Universidade de São Paulo (USP-SP): 2005.

LEWIN, K. Teoria Dinâmica da Personalidade. Tradução de Álvaro Cabral. São Paulo: Editora Cultrix, 1975.

LEITE, J. R. Educação por trás das grades: Uma contribuição ao trabalho educativo, ao prisioneiro e à sociedade. Dissertação de Mestrado. Marília, São Paulo: UNESP, 1997.

LEME, J. A. G. A cela de aula: Tirando a pena com letras. Uma reflexão sobre o sentido da educação nos presídios. Dissertação de Mestrado. Programa de Estudos Pós-Graduados em Educação - Currículo, da Pontifícia Universidade Católica de São Paulo. PUC-SP, 2002.

LESNE, M. \& MYNVIELLE, M. Formation et socialisation. Paris: Paideia, 1990.

LIMA, L. C. Construindo um objecto: para uma análise crítica da investigação portuguesa sobre a escola. In: BARROSO, João (org.). O estudo da escola. Colab. Licínio C. Lima. Portugal: Porto Editora, 1996, pp. 15-35.

LOURENÇO, A. S. As Regularidades e as Singularidades dos Processos Educacionais no Interior de duas Instituições Prisionais e suas Repercussões na Escolarização de Prisioneiros: um contraponto à noção de sistema penitenciário? Dissertação de Mestrado. Programa de Estudos Pós-Graduados em Educação: História, Política, Sociedade, Pontifícia Universidade Católica de São Paulo (PUC-SP), 2005.

O espaço de vida do Agente de Segurança Penitenciária no cárcere: entre gaiolas, ratoeiras e aquários. Curitiba: Juruá, 2011.

ONOFRE, E. M. C. Educação escolar na prisão. Para além das grades: A essência da escola e a possibilidade de resgate da identidade do homem encarcerado. Tese de Doutorado. Araraquara, São Paulo: UNESP, 2002.

PAIXÃO, A. L. Uma saga carcerária. Temas IMESC. Sociologia, Direito, Saúde. São Paulo, v.2, no 2, pp. 97-110, 1985.

PARO. V. H. Administração escolar - Introdução crítica. 9a edição. São Paulo: Cortez, 2000.

PENNA, M. G. O. A escola no interior das prisões: monitores presos. Dissertação de Mestrado. Programa de Estudos Pós-Graduados em Educação: História, Política, Sociedade, Pontifícia Universidade Católica de São Paulo (PUC-SP), 2003. 
PERRENOUD, P. Ofício de aluno e sentido do trabalho escolar. Tradutores: Júlia Ferreira e José Cláudio. Porto, Portugal: Porto Editora, 1995 (Coleção Ciências da Educação).

PORTUGUÊS, M. R. Educação de adultos prisioneiros: possibilidades e contradições da inserção da educação escolar nos programas de reabilitação do sistema penal no estado de São Paulo. Dissertação de Mestrado. Departamento de Educação, da Universidade de São Paulo - USP, 2001.

SALLA, F. A. Educação como Processo de Reabilitação. In: MAIDA, M. J. D. Presídios e Educação. Anais do encontro de monitores de alfabetização de adultos presos do Estado de São Paulo. São Paulo: Fundação Prof. Dr. Manoel Pedro Pimentel FUNAP, 1994, p. 93-98.

SANTOS, S. A educação escolar no sistema prisional sob a ótica dos detentos.

Dissertação de Mestrado. Programa de Estudos Pós-Graduados em Educação: História, Política, Sociedade, da Pontifícia Universidade Católica de São Paulo - PUCSP, 2002.

SYKES, G. M. The society of captives: a study of a maximum security prison. New Jersey - USA: Princeton University Press, 1999.

VIÑAO FRAGO, A. El Espacio y el tiempo escolares como objeto histórico. Contemporaneidade e Educação. Revista semestral de Ciências Sociais e Educação. Instituto de Estudos da Cultura e Educação Continuada - IEC, ano V, nº 07 $-1^{\circ}$ semestre, 2000.

Recebido em: 22/02/2016

Aprovado em: 03/05/2016 